\title{
Optimal Zwitterionic Surfactant Slug for an Improved OilRecovery in Oil Wet Carbonate Rocks - Silurian Dolomite
}

\author{
Yosamin Esanullah ${ }^{1}$, Madison Barth ${ }^{1}$, Benedicta Nwani ${ }^{1}$, Japan Trivedi ${ }^{1}$ \\ ${ }^{1}$ Department of Civil and Environmental Engineering, University of Alberta
}

\begin{abstract}
The increase in energy demand has led to extensive research and development on economically, environmentally and technically feasible ways of improving the ever-growing energy demand. A common derivative of energy is from hydrocarbons, specifically oil. The process of oil recovery can be divided into primary, secondary, and tertiary recovery (also known as enhanced oil recovery). Once the internal pressure of a reservoir has depleted enough during primary and secondary recovery, more advanced techniques in enhanced oil recovery mechanisms are used to recover $50-80 \%$ of oil in the reservoir. Tertiary recovery includes the use of surfactants to reduce interfacial tension (IFT) or alter wettability. In this work, a zwitter ionic surfactant at two different concentrations is evaluated for its ability to reduce the interfacial tension between oil and water, as well as altering wettability in silurian dolomite. To achieve this, fluid-fluid analysis was done by a compatibility test, phase behavior test and interfacial tension measurements. Rock-fluid analysis was also completed by means of floatation test, carried out with carbonate rock particles to analyze the surfactant's ability to alter wettability. Solution $\mathrm{pH}$ measurements were taken to validate the qualitative floatation test results. Results show that the surfactant, chembetaine $\mathrm{C}$ surfactant, is compatible with all ranges of salinities investigated, though was not able to produce a winsor type III microemulsion. The results of the interfacial tension measurements are in line with the phase behavior test, as none of the measurements were at ultra-low values. Surfactant retention is likely to occur with the analyzed zwitterionic surfactant based on the fluid-fluid analysis. Qualitative results from the floatation test show that the wettability of the carbonate rock particles cannot be significantly altered to more water-wet conditions. The $\mathrm{pH}$ of the solution remains at alkaline values, which can be beneficial in enhanced oil recovery in producing soap in situ, also known as saponification. Overall, tests conclude that this zwitterionic surfactant at $1 \%$ concentration would be most effective at $10,000 \mathrm{ppm}$ salinity brine, though overall is not suitable for chemically enhanced oil recovery.
\end{abstract}

Key words:

zwitterionic surfactant, enhanced oil recovery, compatibility test, phase behavior test, interfacial tension, wettability, tertiary oil recovery

Cite as: Esanullah Y., Barth M., Nwani B., and Trivedi J. 2019. Optimal zwitterionic surfactant slug for an improved oil recovery in oil wet carbonate rocks - silurian dolomite. Alberta Academic Review, Vol 2 (2) 27-28, WISEST Special Issue (not peer-reviewed), DOI 10.29173/aar40. 


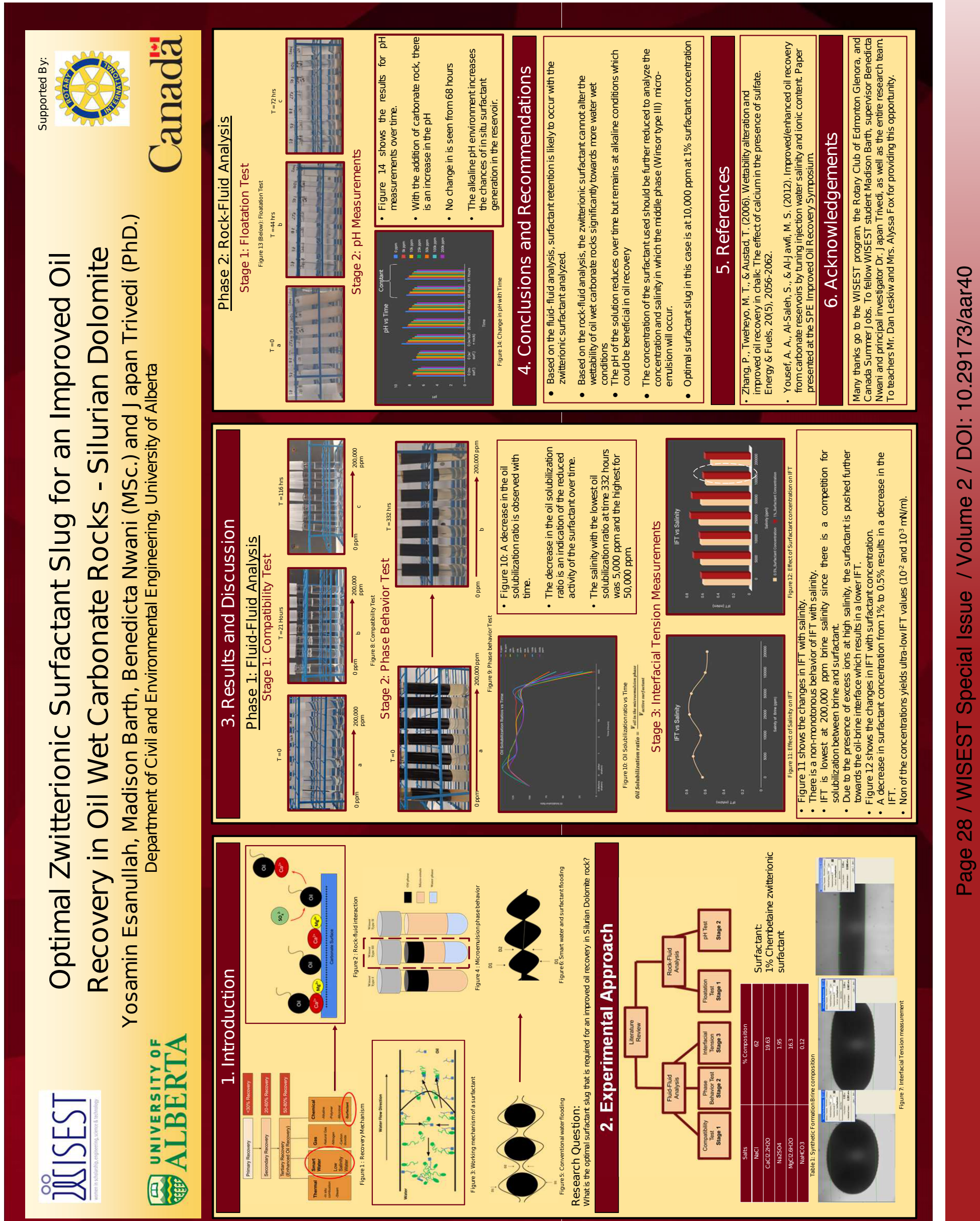

